\title{
The Effectiveness of Group Acceptance and Commitment Therapy on Pain Intensity, Pain Catastrophizing and Pain-Associated Anxiety in Patients with Chronic Pain
}

\author{
Abbas Nasiri \& Hamid Kazemi-Zahrani ${ }^{2}$ \\ ${ }^{1}$ Department of Psychology, Najafabad Branch, Islamic Azad University, Najafabad, Isfahan, Iran \\ ${ }^{2}$ Department of Psychology, Payame Noor University, PO BOX: 19395-3697, Tehran, Iran \\ Correspondence: Hamid Kazemi-Zahrani, Department of Psychology, Payame Noor University, PO BOX: \\ 19395-3697, Tehran, Iran. E-mail: kazemi_psyc@yahoo.com
}

Received: June 10, 2015 Accepted: July 15, 2015 Online Published: September 8, 2015

doi:10.5539/ass.v11n26p112 URL: http://dx.doi.org/10.5539/ass.v11n26p112

\begin{abstract}
This study aimed to evaluate the effectiveness of group-Acceptance and Commitment Therapy (ACT) on the intensity of pain, catastrophizing it and pain-associated anxiety in patients with chronic pain. The research design was quasi-experimental with pretest-posttest and one-month follow-up with control group. The statistical population was all individuals referring to psychological clinics, physical medicine and health centers in Isfahan city who were diagnosed to have chronic pain disorder in 2014. Out of 67 registered patients, 30 patients who had the research criteria were selected by the convenience sampling method and were randomly assigned into two groups each with 15 members. The subjects of the two groups all responded to Chronic Pain Acceptance Questionnaire (CPAQ), Pain Intensity Scale (PIS), Pain Catastrophizing Scale (PCS), and Pain-Anxiety Symptoms Scale (PASS-20). The experimental group received 8 90-minute sessions of Group- Acceptance and Commitment Therapy once a week. The data was assessed in 3 stages of pretest, posttest, and follow-up and was analyzed by multivariable covariance analysis. The results showed that the experimental group had a significant improvement in pain intensity, pain catastrophizing, and pain-associated anxiety $(\mathrm{P}<0 / 01)$ and this improvement was consistent after one-month follow-up. It can be said that Acceptance and Commitment Therapy can be effective on experience of pain of patients with chronic pain.
\end{abstract}

Keywords: Group-Acceptance and Commitment Therapy, Pain intensity, Pain Catastrophizing, Pain-Associated Anxiety, Chronic Pain Disorder

\section{Introduction}

Pain plays a critical protective role in saving humans' life by making us avoid dangerous and unpleasant stimulants. However, uncontrollable and long pain loses its warning and adaptive role and creates various psychological problems for humans (Wicksell, Olsson, \& Hayes, 2011). Pain is a sensational and psychological experience of discomfort which is usually related to the real harm or the factor threatening tissues (International American Chronic Pain Association, 2014). Pain is basically divided into severe and chronic pain. The distinction between the two is in a 3-month interval in clinic works and 6-month interval in researches (Breivik, Collett, Ventafridda, Cohen, Gallacher, 2006). Chronic pain is an overwhelming situation so that it causes not only pain-associated tension and stress but also increasing emotional pressure, demoralization, disappointment, helplessness, and anxiety (Breivik et al., 2006). In a lot of researches, pain intensity, and emotional disorders such as anxiety, cognitive deviations, and physical harm or injury are considered as main predictors of disability in this disorder (Weiner, Rudy, Kime, \& Golla, 2004; Gauntlett - Gilbert \& Eccleston, 2007). Chronic pain has two main dimensions of sensational and affective dimensions. The sensational dimension refers to intensity of pain and affective dimension refers to emotional disorders associated with pain disorder so that Vadivelu, Urman \& Hines (2011) consider anxiety as the most common pain-associated psychiatric disorder. Anxiety can increase one's experience of pain by decreasing his feeling of self-efficiency or self-confidence when facing potential threats (Holland, Breitbart, Jacobsen, Lederberg, Loscalzo, \& McCorkle, 2010). These factors all make a person overestimate his illness and pain and regard it as a catastrophe and the person thinks he is unable to cope with it (Bartley \& Rhudy, 2008). Turner, Jensen \& Romano (2000) studied on 169 patients with chronic pain and found 
out those catastrophic beliefs and coping strategies with pain significantly predict physical disability and depression in patients.

\section{Research Background}

Researchers have shown that biological factors cannot explain vulnerability to the experience of pain disorder, the time of its occurrence or incidence, its process, the acceleration and intensification of its incidences and strokes, or the disability related to the disorder by themselves (Rains, Penzien, McCrory, \& Gray, 2005) since all psychosomatic disorders play a critical role in the emergence and creation of physical symptoms. In treating chronic pain, medical and non-medical treatments are used. Researches indicate that using medical medicines such as opium, anti-depressant, and anti-convulsion drugs only reduces patients' pain only up to 30 to $40 \%$ (McMahon \& Koltzenberg, 2006). Hoffman, Papas, Chatkoff \& Kerns (2007) found out that multiple-therapy approaches have more short-term and long-term effects on pain, emotional reactions, pain experience and pain intensity, and improvement of individuals' daily and occupational performance. One of the components of these treatments or therapies is psychological intervention. In this regard, the concept of acceptance is one of the psychological concepts which have attracted a lot of attention in explaining chronic pain-associated disability.

Psychological acceptance has a prominent role in adapting individuals to a lot of unwanted emotional experiences, memories, and unpleasant thoughts or special physical situation. Some researchers believe that having a psychological acceptance background makes people experience more acceptances when confronting pain and have less avoidance reactions (Hayes \& Strosahl, 2010). Evidences show that individuals who make more effort to stop and remove pain or use distracting strategies for avoiding pain experience more pain and psychological distress in comparison to individuals who face their feelings, emotions, and thoughts related to pain and accept them (Macedo, Latimer, Maher, Hodges, Nicholas, Tonkin, McAuley, \& Stafford, 2008). In Acceptance and Commitment Therapy which is briefly called ACT, the main goal is creating psychological flexibility, that is making somebody able to practically choose the appropriate option among different options and not to do something to avoid thoughts, feelings, memories, or distressing tendencies imposed on the individual (Foreman \& Herbert, 2008). ACT has 6 central main procedures which lead to psychological flexibility including psychological acceptance, psychological awareness, cognitive defusion, self as context, value clearing, and committed action (Hayes, Luoma, Bond, Masuda, \& lillis, 2006; Foreman \& Herbert, 2008). Psychological flexibility and pain acceptance brings about using active coping strategies and evading passive avoiding strategies (McCracken \& Gootirez-Martin, 2011). The review of researches show that most therapeutic interventions of chronic pain focus on relaxation, techniques for reducing anxiety and stress management, problem solving, psychological education, cognitive therapy, behavioral interventions such as distraction, and hypnotism (Rost, Wilson, Buchanan, Hildebrandt, \& Mutch. 2012; Nezo, MaguthNezu, Friedman, Faddis, \& Houts, 1998 ; Nezo, MaguthNezu, Felgoise, McClure, \& Houts, 2003; Coluzzi, Grant, Doroshow, Rhiner, Ferrell \& Rivera, 1995; Jacobsen \& Jim, 2008; Holland et al., 2010). So far, process-oriented approaches which focus only on thoughts and thought patterns and individuals' reaction and response to their thoughts have not been investigated. Therefore, the aim of this research was to study the effectiveness of Acceptance and Commitment Therapy on the psychological indices of patients with chronic pain.

\section{Research Methodology}

The present study is a clinic experimental type with treatment, pretest, posttest, one-month follow-up and control group. The statistical population of the study was all individuals referring to psychological clinics, physical medicine health centers in Isfahan city who were diagnosed to have disorder by psychiatrists and were proved to have chronic pain disorder and not to have other main psychological and personality disorders through clinic interviews by clinic psychologists in 2014. Convenience sampling method was used for sampling. To do so, the researcher referred to Azahra, Sadi Therapeutic and medical centers and specialty clinics in Isfahan city and introduced the research design in some sessions. Those who were interested in participating in the research were registered. Out of all who were registered (67 individuals), 30 individuals were randomly selected and assigned in the control and experimental (intervention) groups. However, the research was done based on the data gathered from 25 individuals because of the drop-out of 1 person in the intervention group and 4 individuals in the control group. The criteria for being included in or excluded from the research were: being diagnosed as having one of chronic pain disorders at least for 3 months by the related physician and based on the structural interview by the clinic experts, level of education (at least primary school), age range between 20 to 45, lack of recognizing the real cause of pain like other physical diseases. The patients received no other psychological treatments or therapies while receiving the research's therapy. In case of receiving other psychological therapies or interventions prior to the research, all of them finished one month before participating in the research. The criteria for excluding participants from the research was being diagnosed to have disorders in axes I and II 
simultaneously based on the diagnosis guide of psychological disorders by the clinic psychologist. In addition, the presence of justifying organic symptoms was a sign of the disease. The treatment group received group Acceptance and Commitment Therapy in 8 sessions. The description of sessions is given below.

\subsection{Therapeutic Sessions of Acceptance and Commitment Therapy}

Session 1

Getting familiar with the members of the group and making a therapeutic relationship, making members familiar with the subject of the research, discussion about the boundaries of confidentiality and secrecy, looking into chronic pain in each member of the group including the duration and type of pain and the used treatments and therapies, the overall assessment and evaluation of distressing thoughts and feelings in members, evaluating methods of controlling these thoughts and feelings, an introduction to creative helplessness, giving an assignment, answering the questionnaires

\section{Session 2}

Getting feedback from the first session, studying the homework or assignment of the previous session and discussing it, continuing creative helplessness, studying the worlds inside and outside of ACT, making individuals eager to quit the inefficient program of change, making individuals understand that control is a problem not a solution, and an introduction to tendency or inclination that is an alternative to control.

Session 3

Getting feedback from the second session and reviewing the reactions and responses to the previous session, continuing the discussion about tendency using ACT metaphors and similarities and exemplifications, introducing values and identifying the individuals' values, making relationships and making individuals understand the concept of tendency alongside with the concept of values, giving an assignment

\section{Session 4}

Getting feedback from the third session and reviewing reactions to the previous session, determining and studying the values of each person, clarification of or clearing values, actions and internal and external barriers and deepening these concepts, an introduction to the concept of defusion, giving an assignment

\section{Session 5}

Getting feedback from the fourth session and reviewing reactions to the previous session, making individuals understand fusion and defusion using metaphors, similarities and exemplifications in ACT, doing experimental exercises for making individuals understand the concept of defusion, introducing mindfulness, and doing one of the exercises of mindfulness, giving an assignment

\section{Session 6}

Getting feedback from the fifth session and reviewing reactions to the previous session, introducing different kinds of fusion, the concept of conceptualized self and educating how to defuse from it, pointing to values and evaluating the adaptation score, doing one of the exercises of mindfulness

\section{Session 7}

Getting feedback from the sixth session and reviewing reactions to the previous session, introducing fusion with life story, mindfulness and emphasizing on being at the present moment or contact with the present moment, referring to values and the necessity of being committed to values

\section{Session 8}

Getting feedback from the seventh session and reviewing reactions to the previous session, introducing the concept of controlling self and summarizing previous sessions and emphasizing on the main processes of Acceptance and Commitment Therapy i.e. Acceptance, Defusion, Self as context, Contact with the present moment, values, and committed action.

The following instruments were used for collecting the data:

\subsection{Acceptance and Action Questionnaire}

There are several versions of AAQ. The first edition includes 16 two-dimensional questions which assess acceptance, mindfulness, and value-oriented action. These two dimensions are called psychological flexibility (Hayes, 2004; Bond et al., 2011). The second version includes 9 questions without any dimension. The 9-question and 16-question questionnaires showed a significant correlation with each other $(\mathrm{r}=0 / 89)$ (Hayes et al., 2006). AAQ- $И$ is a 10-question instrument which showed a good internal consistency $(\alpha=0 / 87)$ and test-retest 
reliability ( $\mathrm{r}=0 / 80)$. AAQ-И includes both positive and negative questions. AAQ- И is correlated with variables that are theoretically related to it. For instance, higher levels of psychological flexibility as assessed by AAQ- И were related to lower levels of overall psychological depression, anxiety, and distress. In addition, higher scores of AAQ-И predicted psychological health (Bond et al., 2011). In Iran, Chranbach's alpha coefficient for this instrument was calculated and reported to be at an acceptable level by Abasi, Molodi and Zarabi (2013).

\subsection{Pain Intensity Scale}

Pain intensity was assessed using a scale of 0 to 10 degrees $(0=$ lack of pain, $10=$ the worst possible pain). The patients were asked to rate or grade their daily average pain in the last week. This index is widely used in research related to pain (e.g. McCracken et al.'s research). In Iran, Afsharzadeh, Rezaee and Yousefzadeh, (2010) evaluated the reliability and validity of the scale in internal investigations.

\subsection{Pain Catastrophizing Scale}

Pain catastrophizing scale was made by Sullivan, Bishop, and Pivik in 1995 with the aim of evaluating the individual's degree of catastrophic thoughts and behaviors. The questionnaire is self-report and consists of 13 subscales or dimensions and needs at least 6 classes of academic education to be responded. PCS was made to evaluate various aspects of pain catastrophizing and for a better understanding of the mechanism of the impact of catastrophizing on pain experience. Factor analysis showed that it includes the subscales of rumination, exaggeration, and helplessness. These three components evaluate negative thoughts associated with pain. Participants are asked to choose a number from 0 (never) to 4 (always) for a description of the frequency of 13 different feelings and thoughts associated with experiencing pain. Lower scores indicate less catastrophizing. The reliability using Cronbach's alpha was obtained to be $0 / 88,0 / 89$, and $0 / 67$ for the subscales of rumination, helplessness, and exaggeration respectively and 0/92 for the whole scale. In addition, test-retest reliability of PSC in a sample of 100 patients with musculoskeletal diseases with a time interval of 21 days was $r=0 / 80$ for the whole scale and was approved to be between 0/67 and 0/81 for the subscales (Mayer, Salovey \& Caruso, 2008). In Iran, this questionnaire was first normalized and used in the study by Davoodi, Yadollah, et al. (2012) and PCS correlation coefficient and the short form of Beck's Depression Inventory were calculated and there was a positive and significant correlation between the score of the whole catastrophizing scale PCS and the short form of Beck's Depression inventory.

\subsection{Pain Anxiety Symptoms Scale}

The questionnaire was made by Lovibond and Lovibond (1995). This scale consists of two forms. The main form consists of 42 statements which evaluate the psychological structures of depression, anxiety, and stress by 14 different statements. Its short form includes 21 statements each measuring one psychological structure or factor by 7 statements. Participants must mark or sign the severity of the frequency of the mentioned issue in each subject matter experienced over the past week. Each question has a Likert scale from 0 to 3. Lovibond and Lovibond (1995) showed that test-retest reliabilities for the subscales of depression, stress, and anxiety were 0/71, $0 / 81$, and 0/79 respectively. For the validity of the scale the correlation coefficients of Beck's Anxiety and Depression Inventories were $0 / 81$ and $0 / 74$ respectively. Therefore, this scale's validity is suitable for being applied in research and diagnostic activities. In the present study, $\alpha=0 / 78, \alpha=0 / 78$, and $\alpha=0 / 79$ for depression, anxiety, and stress respectively obtained by the researcher.

The results obtained by the research instruments were analyzed by descriptive and inferential (multi-variable covariance) statistics by SPSS-20 software.

\section{Results}

The demographic results of the research showed that the individuals participating in the research were $12 \%$ men and $88 \%$ women. Out of this number $12 \%$ had primary school degree, $48 \%$ had diploma, and $40 \%$ had bachelor's degree. In addition, $12 / 5 \%$ were self-employed, $33 / 3 \%$ were employees, and $54 / 2 \%$ were housekeepers. $95 / 8 \%$ of the participants were married and $4 / 2 \%$ was single. The mean of age in the experimental group was $38 / 57$ with the standard deviation of $4 / 25$ and the mean of $41 / 36$ with the standard deviation of $4 / 58$ in the control group. The mean of pain history of the participants in the experimental group was $5 / 45$ with the standard deviation of $3 / 67$ and the mean of 2 with the standard deviation of zero in the control group. In addition, the mean of disease history of the participants in the experimental group was $4 / 21$ with the standard deviation of $2 / 99$ and the mean of 9/71 with the standard deviation of 6/7 in the control group. It should be mentioned that the participants in the research suffered disorders such as rheumatoid arthritis $(30 \%)$, anxiety $(15 \%)$, back pain $(15 \%)$, depression $(5 \%)$, headache $(30 \%)$ and mental obsession $(5 \%)$. The results obtained by the necessary assumptions of doing parametric test showed that the assumption of normal distribution of scores with Shapiro 
Wilk Test is approved for the variables of pain intensity (0/940), pain-associated anxiety (0/0630), pain catastrophizing (0/836) and only the assumption of the equality of variances with Levene's Test is not approved for the variable of pain catastrophizing $(0 / 027)$. Nonetheless, due to the point that the scale of data was interval and the normal distribution of the data, the analysis of covariance test is permitted. The results obtained by investigating group intervention of Acceptance and Commitment Therapy and its effect on pain intensity, pain catastrophizing, and pain-associate anxiety of the patients with chronic pain in post-test and follow-up stages are presented in Table 2 and 3.

Table 2. The results of Mancova analysis on the mean of scores of all variables

\begin{tabular}{cccccccc}
\hline & Value & $\mathrm{F}$ & $\mathrm{df1}$ & $\mathrm{df2}$ & Significance & Eta Square & Power Estimate \\
\hline Wilk's Lambda & $0 / 097$ & $9 / 303$ & $6 / 00$ & $6 / 00$ & $* * 0 / 008$ & $0 / 903$ & $0 / 950$ \\
\hline
\end{tabular}

As it can be seen in Table 2, the significance levels of the test indicate that in post-test and follow-up stages, the mean of the experimental group is reduced in comparison to the control group at least in one of the elements of the research (pain intensity, pain catastrophizing, and pain-associated anxiety) $(\mathrm{P}<0 / 01)$. The degree of this effect or difference is equal to $0 / 903 \%$ i.e. $90 / 3 \%$ of individual differences in the scores of all components of the study (pain intensity, pain catastrophizing, and pain- associated anxiety) is related to the effect of group membership. The statistical power close to 1 indicates sufficient volume of the sample. The results of variance analysis about the effectiveness of ACT pain in the post-test and follow-up is presented in Table 3.

Table 3. The results of Mancova analysis of the effect of group membership on the scores of pain intensity

\begin{tabular}{ccccccccc}
\hline \multicolumn{2}{c}{ Pain Intensity } & $\begin{array}{c}\text { Sum of } \\
\text { Squares }\end{array}$ & df & $\begin{array}{c}\text { Mean of } \\
\text { Squares }\end{array}$ & F & Significance & $\begin{array}{c}\text { Effect } \\
\text { Size }\end{array}$ & $\begin{array}{c}\text { Power } \\
\text { Estimate }\end{array}$ \\
\hline \multirow{2}{*}{ Pretest } & Post-test & $0 / 381$ & 1 & $0 / 381$ & $0 / 107$ & $0 / 750$ & $0 / 010$ & $0 / 060$ \\
& Follow-up & $0 / 409$ & 1 & $0 / 409$ & $0 / 170$ & $0 / 688$ & $0 / 015$ & $0 / 066$ \\
\multirow{2}{*}{ Group } & Post-test & $11 / 923$ & 1 & $11 / 923$ & $3 / 341$ & $* 0 / 045$ & $0 / 223$ & $0 / 883$ \\
& Follow-up & $21 / 215$ & 1 & $21 / 215$ & $8 / 817$ & $* 0 / 013$ & $0 / 445$ & $0 / 771$ \\
\multirow{2}{*}{ Error } & Post-test & $39 / 256$ & 11 & $3 / 569$ & - & - & - & - \\
& Follow-up & $539 / 738$ & 11 & $49 / 067$ & - & - & - & - \\
\hline
\end{tabular}

The results of Table 3 show that this therapy has been effective on the reduction of pain intensity in the post-test and follow-up stages compared to the control group. The degree of this effect in the post-test was $22.3 \%$ and in the follow-up was $44 / 5 \%$ respectively. It is noteworthy that the statistical power in the post-test was $0 / 88$ and in the follow-up was $0 / 77$.

The results of variance analysis about the effectiveness of Acceptance and Commitment Therapy on pain catastrophizing the post-test and follow-up are represented in Table 4.

Table 4. The results of Mancova analysis of the effect of group membership on the scores of pain catastrophizing

\begin{tabular}{ccccccccc}
\hline \multirow{2}{*}{ Pain Catastrophizing } & $\begin{array}{c}\text { Sum of } \\
\text { Squares }\end{array}$ & df & $\begin{array}{c}\text { Mean of } \\
\text { Squares }\end{array}$ & F & Significance & $\begin{array}{c}\text { Effect } \\
\text { Size }\end{array}$ & $\begin{array}{c}\text { Power } \\
\text { Estimate }\end{array}$ \\
\hline \multirow{2}{*}{ Pretest } & Post-test & $11 / 198$ & 1 & $11 / 198$ & $0 / 377$ & $0 / 552$ & $0 / 033$ & $0 / 087$ \\
& Follow-up & $5 / 374$ & 1 & $5 / 374$ & $0 / 492$ & $0 / 498$ & $0 / 043$ & $0 / 098$ \\
\multirow{2}{*}{ Group } & Post-test & $322 / 600$ & 1 & $322 / 600$ & $10 / 846$ & $* * 0 / 007$ & $0 / 496$ & $0 / 850$ \\
& Follow-up & $499 / 911$ & 1 & $499 / 911$ & $45 / 724$ & $* * 0 / 001$ & $0 / 806$ & $0 / 999$ \\
\multirow{2}{*}{ Error } & Post-test & $327 / 166$ & 11 & $29 / 742$ & - & - & - & - \\
& Follow-up & $120 / 266$ & 11 & $10 / 933$ & - & - & - & - \\
\hline
\end{tabular}


As it can be seen in Table 4, there is a significant difference between modified means of pain catastrophizing scores of the participants by group membership (experimental and control group) in the post-test and follow-up $(\mathrm{P}<0 / 01)$. Therefore, the assumption was confirmed and Acceptance and Commitment Therapy was effective on the reduction of pain catastrophizing scores in the post-test and follow-up in the experimental group. The degree of this effect was $49 / 6 \%$, and $80 / 6 \%$ in the post-test and follow-up stages respectively. It is notable that the statistical power was $0 / 85$ in the pre-test and 1 in the follow-up.

The results of variance analysis on the effectiveness of Acceptance and Commitment Therapy on pain-associated anxiety in the post-test and follow-up are shown in Table 5.

Table 5. The results of Mancova analysis on the effect of group membership on the scores of pain-associated anxiety

\begin{tabular}{ccccccccc}
\hline \multirow{2}{*}{ Pain-associated anxiety } & $\begin{array}{c}\text { Sum of } \\
\text { Squares }\end{array}$ & df & $\begin{array}{c}\text { Mean of } \\
\text { Squares }\end{array}$ & F & Significance & $\begin{array}{c}\text { Effect } \\
\text { Size }\end{array}$ & $\begin{array}{c}\text { Power } \\
\text { Estimate }\end{array}$ \\
\hline \multirow{2}{*}{ Pretest } & Post-test & $70 / 002$ & 1 & $70 / 002$ & $1 / 427$ & $0 / 257$ & $0 / 115$ & $0 / 194$ \\
& Follow-up & $29 / 854$ & 1 & $29 / 854$ & $0 / 607$ & $0 / 452$ & $0 / 052$ & $0 / 110$ \\
\multirow{2}{*}{ Group } & Post-test & $1713 / 810$ & 1 & $1713 / 810$ & $34 / 928$ & $* * 0 / 001$ & $0 / 760$ & $0 / 999$ \\
& Follow-up & $1885 / 044$ & 1 & $1885 / 044$ & $38 / 321$ & $* * 0 / 001$ & $0 / 777$ & $0 / 999$ \\
\multirow{2}{*}{ Error } & Post-test & $539 / 738$ & 11 & $49 / 067$ & - & - & - & - \\
& Follow-up & $541 / 102$ & 11 & $49 / 191$ & - & - & - & - \\
\hline
\end{tabular}

The results of Table 5 show that Acceptance and Commitment Therapy has been effective on the reduction of the scores of pain-associated anxiety in the post-test and follow-up stages in the experimental group. The degree of this effect was $76 \%$ and $77 / 7 \%$ in the post-test and follow-up stages. It is noticeable that the statistical power was $0 / 76$ and $0 / 78$ in the post-test and follow-up stages respectively.

\section{Discussion and Conclusion}

This study aimed to evaluate the effectiveness of group Acceptance and Commitment Therapy (ACT) on the intensity of pain, catastrophizing it \& pain-associated anxiety in patients with chronic pain. The results of the research revealed that Acceptance and Commitment Therapy has been effective on the reduction of the pain intensity, pain-associated catastrophic thoughts, and pain-associated anxiety in the post-test stage and these changes were consistent in the one-month follow-up. These results are in line with the results obtained by Baranoff, Hanrahan, Kapur, \& Connor (2013), Vowles, McCracken, O'Brien (2011) and Nordin and Rosman(2012). On the intensity of experienced pain results are in line with the results obtained by Vowles and McCracken (2008) and Poppe et al. (2011). Vowles et al. (2008) by studying 344 patients with chronic pain showed that acceptance indirectly improves patients' psychological and physical functioning or performance by modifying catastrophic thoughts on depression, anxiety and avoidance. In addition, Poppe et al. (2011) showed that pain intensity, pain interference, and pain duration were not significantly related to acceptance, while catastrophizing is negatively and significantly related to acceptance and catastrophizing modifies the relationship between the personality feature of avoidance and acceptance. In the present research, the techniques of acceptance and commitment could target pain signs well. In this therapy, pain exposure within sessions was not used. The exercises of behavioral commitment necessarily involved facing and exposure with pain situations outside sessions. Using defusion and acceptance reduced the degree and intensity of these situations for patients. In this intervention, pain intensity was reduced in patients with chronic pain by reducing anxiety by focusing on techniques of acceptance, defusion, detailed discussions about values, and individuals' goals. In this therapy, increasing individuals' tendency to experience internal events as they are was emphasized instead of focusing on exposure. Here, the goal was to help a person to experience feeling pain just as a feeling and to do what is important in his/her life in line with his/her values rather than responding to the feeling i.e. feeling pain in itself was not the issue, but the main issue was the individual's effort to respond to feeling pain (i.e. coping with pain). In fact, the aim of this therapy was increasing the individual's behavioral treasury while facing dangerous events and disasters (such as pain), what is called psychological flexibility. The results of this research are in line with the findings obtained by McCracken, Vowles \& Eccleston (2007). And McCracken, \& Zhao-O'brrien (2010) showed that the participants in this kind of therapy scored better in pain intensity, reports of pain and intensity, 
the frequency of pain-associated anxiety symptoms and gradually their predictions improved. In fact, the central processes of ACT teach the client how to leave and quit thought avoiding and feeling pain, to defuse from pain thoughts and feelings, to reinforce observing self rather than conceptualized self, to accept pain internal events rather than controlling them, to clear his values and address them. One of the most important techniques of this therapy is mindfulness which was particularly emphasized in this research and was practiced almost in all sessions of therapy. Schütze, Rees, Preece, \& Schütze, (2010) emphasized that mindfulness significantly and negatively predicts pain intensity, negative emotions, pain catastrophizing, pain-associated fear, alertness to pain, and inability to function and explains $17 \%$ and $41 \%$ of their variances. Hierarchical regression analysis showed that mindfulness by itself predicts catastrophizing by controlling other variables and modifies the relationship between pain intensity and catastrophizing. In fact, mindfulness makes the person aware of his negative thoughts and emotions and reduces their effects by cognitive defusion and bringing the person to the present moment (two fundamental processes in ACT). Another process which is emphasized in ACT and had a prominent role in this therapy protocol is committed action. Besides bringing about the realization of goals and the happiness resulting from it and increasing patients' life satisfaction, encouraging patients to clarify values (value clearing), determine goals, predict obstacles and hindrances, and finally have commitment to do actions in line with achieving goals and moving towards values despite having pain (by accepting pain) relieves them of being trapped in a loop of negative thoughts and emotions (such as anxiety, catastrophizing, disappointment, despair), which in turn increase pain intensity (McWilliams, Goodwin, \& Cox 2004). This peripheral benefit in ACT is one of the main processes in CBT i.e. distracting attention. Acceptance indirectly improves patients' psychological and physical health by modifying catastrophizing effects on depression, anxiety and avoidance (e.g. Vowles et al., 2008; Meyer, Teshopp, Sprott, \& Mannion, 2009). In this regard, McCracken and Zhao-O'brrien (2010) showed that if people with chronic pain accept their negative experiences without trying to control them, they would have better performance and suffer less and overall acceptance has a unique role in reducing pain and anxiety in patients with chronic pain beyond similar processes such as pain acceptance or mindfulness. The results of the research showed that Acceptance and Commitment Therapy has a significant effect on decreasing the intensity of pain-associated anxiety in both the post-test and follow-up. Based on acceptance approach and time commitment, patients with chronic pain experience fear or anxiety and do an action to avoid pain which makes them suffer more emotional effects and weakens their performance (Heuts, Vlaeyen, Roelofs, de Bie, \& Aretz, 2004). On the other hand, Kratz, Davis and Zavtra (2007) showed that pain acceptance is a predictor of positive therapeutic effects. Acceptance helps patients to separate themselves from their own personal experience (cognitive defusion) and makes patients use less emotional reasons such as anxiety to explain their behavior and address the experience of the consequences of their actions instead of focusing on thoughts and feelings. Keogh, Book, Thomas, Giddins, \& Eccleston, (2010) also stressed that acceptance, mindfulness, and values reduce the effect of sensitivity to anxiety. Mindfulness techniques are useful for patients with pain-associated anxiety and disability. Therefore, for the explanation of these findings, it can be said that two main processes for reducing negative emotions such as anxiety in patients with chronic pain are acceptance and mindfulness. Convenience sampling method, lack of comparing the therapy with other approved therapies, lack of attention to disorders associated with chronic pain, heterogeneous participants in terms of demographic variables are the limitations of this research. It is suggested that this therapy would be studied and investigated in future with long-term 6-month follow-up and considering other psychological indexes affecting the effectiveness of the therapy in patients who are diagnosed to have chronic pain at early stage.

\section{References}

Abasi, E., Fti, L., Molodi, R., \& Zarabi, H. (2013). Psychometric properties pf Persian version of acceptance and action questionnaire=ii. Journal of psychological models and methods, 3(10), 65-80.

Afsharzadeh, T., Rezaee, S., \& Yousefzadeh, Sh. (2010). The relationship between fear of movement and pain intensity with sensory disability in patients with chronic low back pain. Tavanbakhshi Journal, 11(2), 21-28.

Baranoff, J., Hanrahan, S. J., Kapur, D., \& Connor, J. P. (2013). Acceptance as a process variable in relation to catastrophizing in multidisciplinary pain treatment. EuropeanJournal of Pain, 17(1), 101-110.

Bartley, E. J., \& Rhudy, J. L. (2008). The influence of pain catastrophizing on experimentally induced emotion and emotional modulation of nociception. J Pain, (5), 388-396.

Bond, F. W., Hayes, S. C., Baer, R. A., Carpenter, K. C., Guenole, N., Orcutt, H. K., ... Zettle, R. D. (2011). Preliminary psychometric properties of the Acceptance and Action Questionnaire - II: A revised measure of psychological flexibility and acceptance. Behavior Therapy, 42, 676-688.

Breivik, H., Collett, B., Ventafridda, V., Cohen, R., \& Gallacher, D. (2006). Survey of chronic pain in Europe: 
prevalence, impact on daily life, and treatment. Eur J Pain, (10), 287-333.

Coluzzi, P. H., Grant, M., Doroshow, J. H., Rhiner, M., Ferrell, B., \& Rivera, L. (1995). Survey of the provision of supportive care services at National Cancer Institutedesignated cancer centers. J Clin Oncol, 13(3), 756-764.

Davoodi, I., Yadollah, Z., Mozafaripoor Sisakht, E., Nargesi, F., \& Karim M. (2012). The relationship between pain catastrophizing, pain anxiety, Mood neuroticism, social support, coping strategies with functional disability in patients with rheumatoid. Journal of Health Psychology, 1(1), 1-17.

Forman, E. M., \& Herbert, J. D. (2008). New direction in cognitive behavior therapy: acceptance based therapies. In w.o'donohue, je. Fisher (Eds.), Cognitive behavior therapy: Applying empirically supported treatment in your practice (2nd ed., pp. 263 - 265). Hoboken, NJ: Wiley.

Gauntlett - Gilbert, J., \& Eccleston, C. (2007). Disability in adolescents with chronic pain: patterns and predictors across different domains of functioning. Pain, 131(1), 132-141.

Hayes, S. C., \& Strosahl, K. D. (2010). A Practical Guide to Acceptance and Commitment Therapy. New York: Springer Science and Business Media Inc.

Hayes, S. C., Luoma, J. B., Bond, F. W., Masuda, A., \& Lillis, J. (2006). Acceptanceand CommitmentTherapy: Model, processed and outcomes. Journal of Behavior Research and Therapy, 44(1), 1-25.

Hayes. S. C. (2004). Acceptance and Commitment Therapy, relational frame theory, and the third wave of behavioral and cognitive therapies. Behavior therapy, 35(4), 639-665.

Heuts, P. H., Vlaeyen, J. W., Roelofs, J., de Bie, R. A., \& Aretz, K. (2004). Pain-related fear and daily functioning in patients with osteoarthritis. Pain, 110(1), 228-235.

Hoffman, B. M., Papas, R. K., Chatkoff, D. K., \& Kerns, R. D. (2007). Meta-Analysis of Psychological Interventions for Chronic Low Back Pain. Orig Res Article Health Psychol, 26(1), 1-9.

Holland, J. C., Breitbart, W. S., Jacobsen, P. B., Lederberg, M. S., Loscalzo, M. J., \& McCorkle, R. (2010). Psycho-oncology. Oxford University Press

International Association for the Study of Pain (IASP, 2014).

Jacobsen, P. B., \& Jim, H. S. (2008) Psychosocial interventions for anxiety and depression in adult cancer patients: achievements and challenges. $C A, 58(4), 214-230$.

Keogh, E., Book, K., Thomas, J., Giddins, G., \& Eccleston, C. (2010). Predicting pain and disability in patients with hand fractures: Comparing pain anxiety, anxiety sensitivity and pain catastrophizing. European Journnal of pain, 14(4), 446-451.

Kratz, A. L., Davis, M. C., \& Zautra, A. J. (2007). Pain acceptance Moderates the relation between pain and negative affect in Female osteoarthritis and Fibromyalgia patients. Anals of Behavioral Medicine, 33(3), 291- 361.

Lovibond, P. F., \& Lovibond, S. H. (1995). The structure ofnegative emotional states: Comparison of the Depression Anxiety Stress Scales (DASS) with the Beck Depression and Anxiety Inventories. BehavResTher, 33(3), 335-43.

Macedo, L. G., Latimer, J., Maher, C. G., Hodges, P. W., Nicholas, M., Tonkin, L., McAuley, J. H., \& Stafford, R. (2008). Motor control or graded activity exercises for chronic low back pain? A randomize controlled trial. BMC Musculoskelet Disord, 5(9), 65.

McCracken, L. M., \& Zhao-O'brrien, J. (2010). General Psychological acceptance and chronic pain: There is more to accept than the pain itself. European Journal of pain, 14(2), 170-175.

McCracken, L. M., \& Gutierrez-Martinez, O. (2011). Processes of change in psychological Flexibility in an Interdisciplinary Group-Based Treatment for Chronic pain Based on Acceptance and Commitment Therapy. Pain research. University of Bath Press.

McCracken, L. M., Vowles, K. E., \& Eccleston, C. (2007). Processes of change in treatment for chronic pain: The contributions of pain, acceptance, and catastrophizing. European Journal of Pain, 11(7), 779-787.

McMahon, S. B., \& Koltzenber, M. (2006). Textbook of Pain. Elsevier: Churchill: Livingstone.

McWilliams, L. A., Goodwin, R. D., \& Cox, B. J. (2004). Depression and anxiety associated with three pain conditions: results from a nationally representative sample. Pain, 111(1-2), 77-83. 
Meyer, K., Teshopp, A., Sprott, H., \& Mannion, A. F. (2009). Association between catastrophizing and self- rated pain and disability in patients with chronic low back pain. Journal of Rehabilitation medicine, 41(8), 620-625.

Nezu, A. M., MaguthNezu, C., Friedman, S. H., Faddis, S., \& Houts, P. S. (1998). Helping cancer patients cope. A problem solving approach. Washington, DC: American Psychological Association.

Nezu, A. M., Nezu, C. M., Felgoise, S., McClure, K. S., Houts, P. S. (2003). Project Genesis: assessing the efficacy of problem-solving therapy for distressed adult cancer patients. J Consult ClinPsychol, 71(6), 1036-1048.

Nordin, L., \& Rorsman, I. (2012). Cognitive Behavioral therapy in Multipe sclerosis. J Rehabil Med, 44, 87-90.

Poppe, C., Crombez, G., Devulder, J., Hanoulle, I., Vogelaers, D., \& Petrovic, M. (2011). Personality traits in chronic pain patients are associated with low acceptance and catastrophizing about pain. Actaclinicabelgica, $66(3), 209-215$.

Rains, C. J., Penzien, D. B., McCrory, D., \& Gray, R. N. (2005). Behavioral Headache Treatment: History, Review of the Empirical Literature, and Methodological Critique. Headache, 45(2), 92-109.

Rost, A. D., Wilson, K., Buchanan, E., Hildebandt, M. J., \& Mutch, D. (2012). Improving psychological adjustment among late- stage ovarian cancorPatiennts: Examining The role of avoidance in treatment. Cognitive and Behavioral practice, 19(4), 508-517.

Schütze, R., Rees, C., Preece, M., \& Schütze, M. (2010). Low mindfulness predicts pain catastrophizing in a fear-avoidance model of chronic pain. Pain, 148(1), 120.

Sullivan, M. J. L., Bishop, S. R., \& Pivik, J. (1995). The Pain Catastrophizing Scale: Development and validation. Psychol Assess, 7(4), 524-532.

Turner, J. A., Jensen, M. P., \& Romano, J. M. (2000). Do beliefs, coping, and catastrophizing independently predict functioning in patients with chronic pain? Pain, 85(1-2), 115-125.

Vadivelu, N., Urman, R. D., \& Hines, R. L. (2011). Essentials of Pain Management. Springer.

Vowles, K. E., \& McCracken, L. M. (2008). Acceptance and values-based action inchronic pain: A study of treatment effectiveness and process. Journal of Consulting and Clinical Psychology, 76(3), 397-407.

Vowles, K. E., McCracken, L. M., \& O'Brien, J. Z. (2011). Acceptance and values-based action in chronic pain: A three-year follow-up analysis of treatment effectiveness and process. Behaviour research and therapy, 49(11), 748-755.

Weiner, D. K., Rudy, T. E., Kime, Y. S., \& Golla, S. (2004). Do medical factors predict disability in older adults with persistent low back pain? Pain, 112, 214-220.

Wicksell, R. K., Olsson, G. L., \& Hayes. C. S. (2011). Mediators of change in Acceptance and Commitment Therapy for pediatric chronic pain. Pain, 152(12), 2792-2801.

\section{Copyrights}

Copyright for this article is retained by the author(s), with first publication rights granted to the journal.

This is an open-access article distributed under the terms and conditions of the Creative Commons Attribution license (http://creativecommons.org/licenses/by/3.0/). 